\title{
Primary renal mixed tumor characterized by marked proliferation of osteoblast-like cells with osteoid formation in a swine
}

\author{
Yuki OSHIMA ${ }^{1) *}$, Yuri NAKAGAWA ${ }^{1)}$, Tsutae KASHIMA ${ }^{1)}$, Masako MATSUNAGA ${ }^{1)}$, \\ Shohei KUSHIMA ${ }^{1)}$ and Yukichi TANAKA ${ }^{2)}$
}

1)Meat Inspection Station, Kanagawa Prefectural Government, 892-1 Sakai, Atsugi, Kanagawa 243-0022, Japan
${ }^{2)}$ Kanagawa Prefectural Hospital Organization Kanagawa Children's Medical Center, 2-138-4 Mutsukawa, Minami-ku, Yokohama, Kanagawa 232-8555, Japan

J. Vet. Med. Sci.

80(1): 112-115, 2018

doi: 10.1292/jvms.17-0171

Received: 31 March 2017

Accepted: 18 November 2017

Published online in J-STAGE:

1 December 2017
ABSTRACT. Renal mixed tumor characterized by the absence of nephrogenic blastema and the presence of predominant osteoid-producing osteoblast-like cells occurred in the kidney of a 6-month-old, hybrid, female pig. At the post-mortem examination, the tumor was found as a calcified grayish-white mass at the cranial end of the left kidney. Histologically the tumor consisted of 3 growth areas of poorly differentiated spindle cells, osteoid-producing osteoblastlike cells, and luminal epithelial cells. Transition from the spindle cells to the osteoblast-like cells or the luminal epithelial cells was observed. Immunohistochemically, the spindle cells and the osteoblast-like cells were consistently positive for $\beta$-catenin. Although the luminal epithelial cells and adjacent spindle cells were positive for cytokeratin, these 3 types of tumor cells were consistently negative for WT1. The tumor was diagnosed as primary renal mixed tumor characterized by marked proliferation of osteoblast-like cells with osteoid formation.

KEY WORDS: kidney, mixed tumor, osteoid, swine

Mixed tumors contain two or more neoplastic tissue components and are considered to be derived from pluripotential cells that have the ability to differentiate into multiple directions [9]. In pigs, nephroblastoma is known as the most common primary renal tumors, however, little is known of mixed tumor other than nephroblastoma [6]. We encountered a rare case of mixed tumor characterized by mesenchymal cell growth with osteoid and epithelial cell growth with luminal structure. In humans, ossifying renal tumor of infancy (ORTI), a rare benign pediatric renal tumor, has been described by the histological characteristics of marked osteoid formation, osteoblast-like cells and spindle cells, which resembled the present case closely $[5,7,14,15]$. In dogs, sarcomatoid renal cell carcinoma (SRCC) also showed similar histological future of sarcomatoid tissue with osteogenic differentiation [16]. In this report, a rare case of swine mixed tumor we encountered is distinguished from swine ordinary nephroblastoma at the histological and immunohistochemical aspects, and discussed about the histological similarity with ORTI and SRCC.

A 6-month-old, hybrid, female pig was slaughtered at the Kanagawa meat center. No abnormalities were observed at the ante-mortem inspection. At the carcass inspection, a grayish-white mass, $5.0 \times 3.5 \times 2.0 \mathrm{~cm}$, which was odd-shaped with multiple millet seed-sized, calcified nodules on the surface or cross-section, was found at the cranial end of the left kidney (Fig. 1). The tumor lacked a capsule but the border between the mass and adjacent renal tissue was relatively clear. Small hemorrhagic foci were dispersed in the mass. No neoplastic lesion was recognized in the other organs.

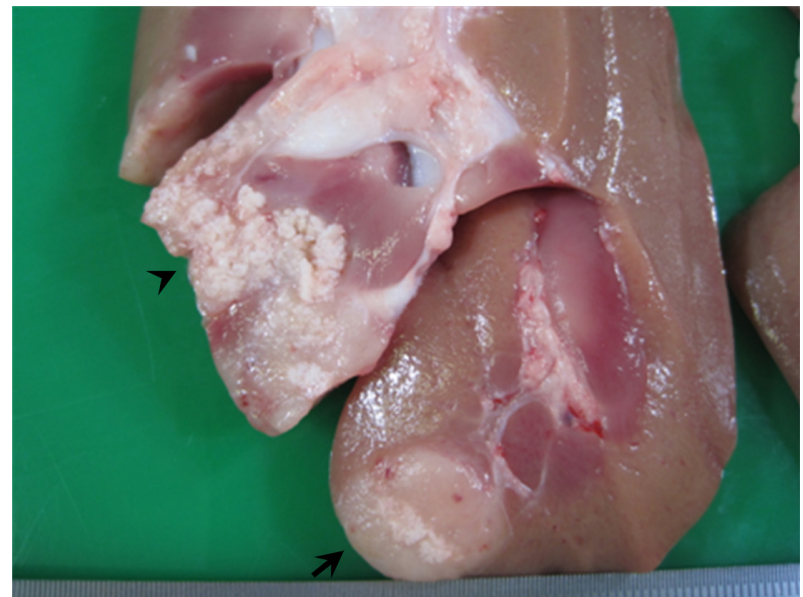

Fig. 1. Gross finding of the tumor: Grayish-white, medullary lesion with calcified core (arrow) and staghone-like lesion with largely calcified areas (arrowhead) are seen.

*Correspondence to: Oshima, Y.: oshima.nbw@pref.kanagawa.jp

O2018 The Japanese Society of Veterinary Science

This is an open-access article distributed under the terms of the Creative Commons Attribution Non-Commercial No Derivatives (by-nc-nd) License. (CC-BY-NC-ND 4.0: https://creativecommons.org/licenses/by-nc-nd/4.o/) 

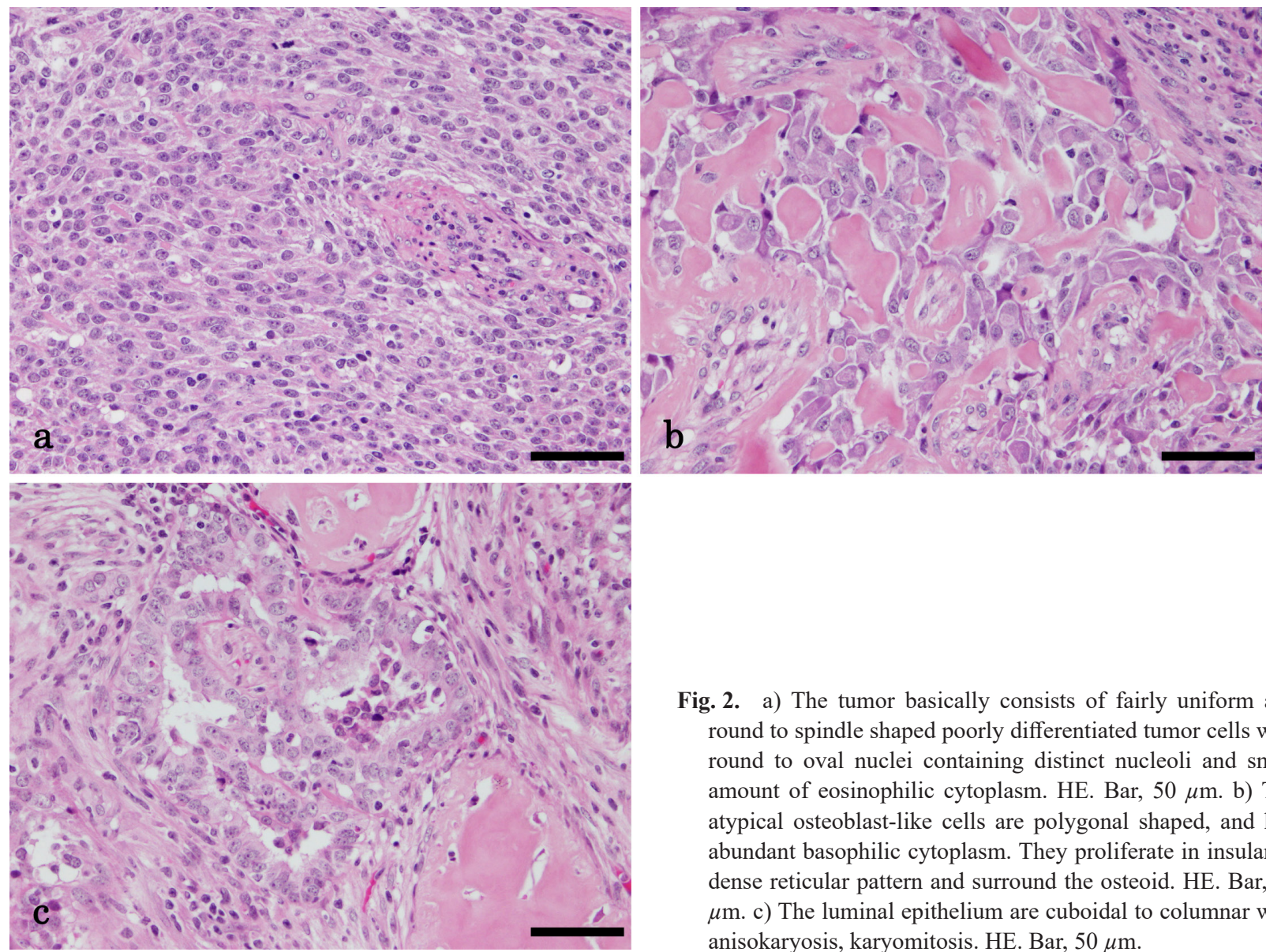

Fig. 2. a) The tumor basically consists of fairly uniform and round to spindle shaped poorly differentiated tumor cells with round to oval nuclei containing distinct nucleoli and small amount of eosinophilic cytoplasm. HE. Bar, $50 \mu \mathrm{m}$. b) The atypical osteoblast-like cells are polygonal shaped, and had abundant basophilic cytoplasm. They proliferate in insular or dense reticular pattern and surround the osteoid. HE. Bar, 50 $\mu \mathrm{m}$. c) The luminal epithelium are cuboidal to columnar with anisokaryosis, karyomitosis. HE. Bar, $50 \mu \mathrm{m}$.

Tissue samples were fixed in 10\% neutral-buffered formalin and were embedded in paraffin wax. A portion of calcified samples was decalcified in $10 \%$ Na2EDTA for several days before embedding. Four- $\mu \mathrm{m}$ sections were cut and stained with hematoxylin and eosin (HE). For immunohistochemical examination, a polymer method (EnVision System-HRP; Dako, Tokyo, Japan) was used on deparaffinized sections with primary antibodies, including mouse monoclonal anti-human cytokeratin (clone AE1/AE3; Dako), mouse monoclonal anti-human epithelial membrane antigen (EMA, clone E29; Dako), mouse monoclonal anti-human $\beta$-catenin (clone 14/B-catenin; BD Transduction Laboratories, Lexington, KY, U.S.A.) and rabbit polyclonal anti-human WT1 (clone C-19; Santa Cruze Biotechnology, Dallas, TX, U.S.A.). Before incubation with primary antibodies, deparaffinized sections were pretreated with microwave heating in Tris/EDTA buffer (pH9.0) for $20 \mathrm{~min}$ at $90^{\circ} \mathrm{C}$. Polymer reagent (Peroxidase-labeled polymerconjugated to goat anti-mouse and anti-rabbit $\operatorname{IgG}$ ) was used as secondary antibodies. The reaction products were visualized by 3,3'-diaminobenzidine tetrahydrochloride (Dako) and the sections were counter-stained with hematoxylin. As a positive control for immunostaining of WT1, we used paraffin sections of a swine nephroblastoma.

Histologically, the mass was mainly composed of 3 growth areas of poorly differentiated tumor cells, osteoblast-like cells with osteoid of varying size, and epithelial cells forming the luminal structures. Although the proportion of these components varied by site, the area of osteoblast-like cells with osteoid accounted for the largest portion of the tumor, whereas the epithelial cells occupied the smallest area. The poorly differentiated tumor cells were round to spindle shaped with round to oval nuclei containing distinct nucleoli, and small amount of eosinophilic cytoplasm (Fig. 2a). Mitotic figures were noted often in the poorly differentiated tumor cells (12 mitoses in 10 consecutive high power fields). The atypical osteoblast-like cells were polygonal shaped, and had abundant basophilic cytoplasm. They proliferated in insular or dense reticular pattern and surrounded the osteoid (Fig. 2b). The form and amount of osteoid was highly variable. Transition from the poorly differentiated tumor cells to the osteoblast-like cells was observed.

The epithelial cells of the luminal structures were cuboidal to columnar and showed anisokaryosis, karyomitosis (Fig. 2c). The luminal epithelial cells were scattered among the dense sheet of poorly differentiated tumor cells, or predominated in some areas. They were apparently distinguished from the pre-existing glomeruli and renal tubules involved by the presence of their cytological atypia. Transition from the poorly differentiated tumor cells to the luminal epithelial cells was also observed.

Immunohistochemical examination showed that the poorly differentiated tumor cells and osteoblast-like cells expressed $\beta$-catenin in the cytoplasm and the nuclei, and the renal tubular epithelium showed positive reaction to the $\beta$-catenin in the cytoplasmic membrane (Fig. 3a). The luminal epithelial cells and some of poorly differentiated tumor cells were positive for 

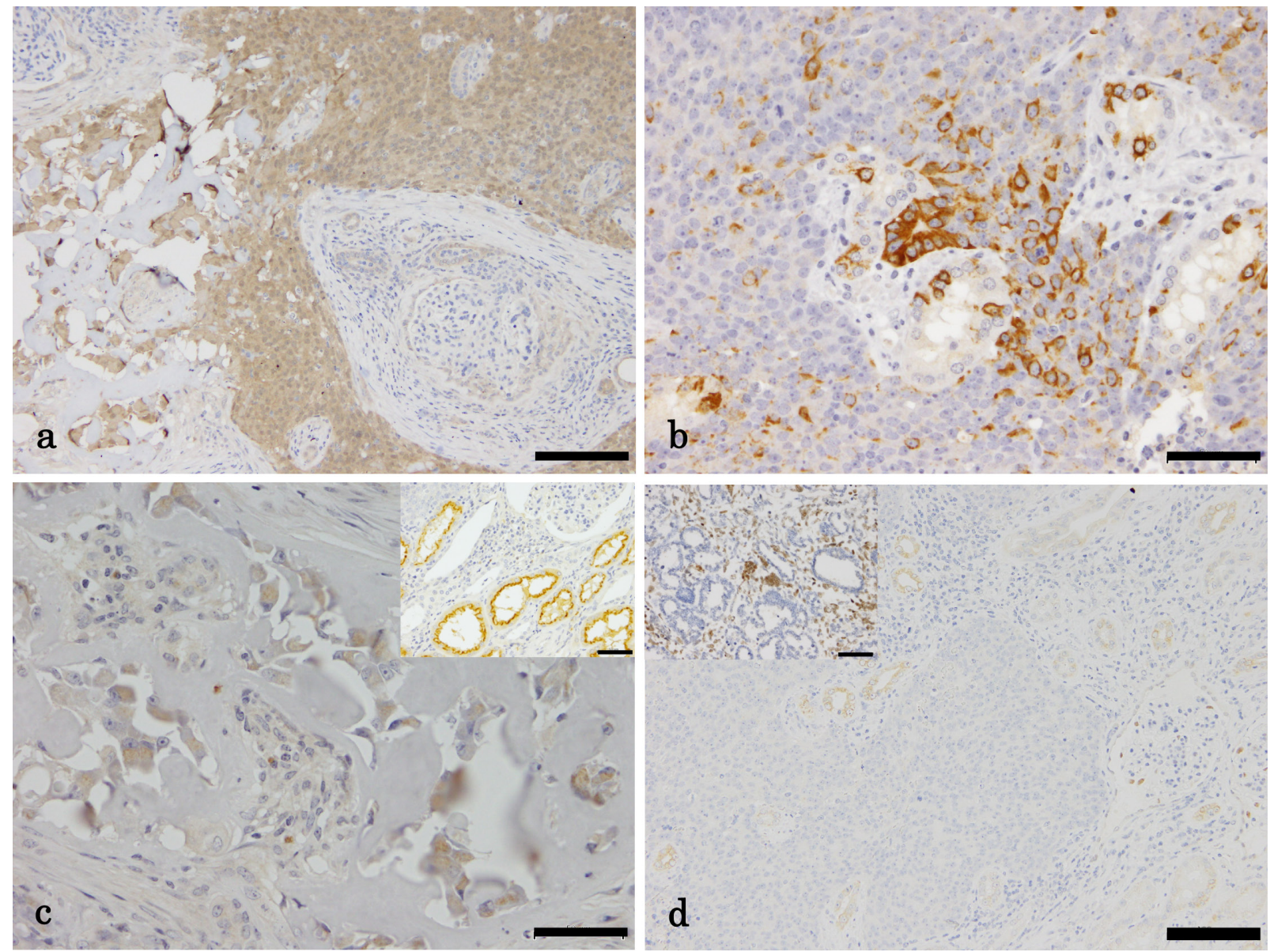

Fig. 3. a) The poorly differentiated tumor cells and osteoblast-like cells express $\beta$-catenin in the cytoplasm and the nuclei. IHC. Bar, $100 \mu \mathrm{m}$. b) The luminal epithelium and some poorly differentiated tumor cells are positive for cytokeratin. IHC. Bar, $50 \mu \mathrm{m}$. c) EMA is only expressed in the cytoplasm of the osteoblast-like cells but in the other tumor components. IHC. Bar, $50 \mu \mathrm{m}$. Inset; The adjacent renal tubular epithelium show positive reaction for EMA in the cytoplasmic membrane. IHC. Bar, $50 \mu \mathrm{m}$. d) Nuclear staining for WT1 is absent in any of the tumor cells. IHC. Bar, $100 \mu \mathrm{m}$. Inset; The blastemal cells of nephroblastoma used as positive control are positive for WT1. IHC. Bar, $50 \mu \mathrm{m}$.

cytokeratin (Fig. 3b). EMA was expressed in the cytoplasm of the osteoblast-like cells but not in the luminal epithelial cells and the poorly differentiated tumor cells (Fig. 3c), while adjacent renal tubular epithelium showed positive reaction in the cytoplasmic membrane (Fig. 3c; inset). On the other hand, any of the tumor cells were consistently negative for WT1 although the nuclei of some pre-existing podocytes were positive (Fig. 3d). In one case of nephroblastoma used as a positive control, the nuclei of neoplastic blastemal cells were often positive for WT1 (Fig. 3d; inset). Immunoreactivity of individual components in tumor tissue is summarized in Table 1.

Histological and immunohistochemical findings showed that the 3 types of neoplastic cells as poorly differentiated tumor cells, osteoid-producing osteoblast-like cells and atypical luminal epithelial cells, the present case was diagnosed as primary renal mixed tumor. The differential diagnosis included nephroblastoma, SRCC and ORTI.

Nephroblastoma is the most frequently observed renal neoplasms of the pig, accounting for approximately $40 \%$ of all porcine neoplasia [12]. The tumor is a triphasic mixture of embryonic epithelium (glomerular buds and tubules), metanephric blastema and myxomatous mesenchyme in various amounts [11]. Nephroblastoma appeared similar to the present case in that both tumors contain the cellular components of both epithelial and mesenchymal origin [2, 15]. However, this case was lack of blastemal cells that represent their characteristic morphology with oval or round, hyperchromatic nuclei and scant cytoplasm [2, 4], and their positive staining for WT1 $[2,3]$. These results indicate that the poorly differentiated tumor cells are clearly distinct from the metanephric blastemal cells included in nephroblastoma.

Renal cell carcinoma (RCC) is a malignant epithelial tumor without embryonal differentiation. Histologic types of RCC seen in animals are solid, tubular, papillary or cystic (multilocular cystic) and one of the most common histologic characteristics is a mixture of these various cell types. Sarcomatoid features can be found rarely in RCC and when seen there is an obvious transition from one of the epithelial patterns into a spindle cell tumor with high cellular and nuclear density [11]. In dogs, SRCC with osteogenic differentiation was reported and closely similar to the present case in that both tumors were composed of sarcomatoid 
Table1. Immunoreactivity of individual components in tumor tissue

\begin{tabular}{lcccc}
\hline \multicolumn{1}{c}{ Tumor components } & Cytokeratin & Beta-catenin & WT1 & EMA \\
\hline Poorly defferentiated tumor cell & $-/+$ & + & - & - \\
Osteoblast-like cell & - & + & - & + \\
Luminal epithelial cell & + & + & - & - \\
\hline
\end{tabular}

+: positive, -: negative, $-/+$ : partially positive.

tissue made up of spindle cells, polygonal cells with an abundant osteoid matrix and atypical epithelial cells [16]. In the report, neoplastic epithelial cells were organized to form papillae and the same degree of reactivity was observed for cytokeratin in papillary structures, as well as in mesenchymal tumor cells, indicated the transition from epithelial neoplastic cells to mesenchymal tumor cells. Likewise, in the present case, the positive reaction to the cytokeratin shown in some poorly differentiated tumor cells represented the epithelial origin of this tumor cells and the mesenchymal components such as the poorly defferentiated tumor cells were considered to be generate from neoplastic epithelial cells, presumably as a consequence of dedifferentiation. Hence, the present case is likely to be SRCC.

Marked osteoid formation by the osteoblast-like tumor cells was a notable histological feature of the present case. Ossifying lesion is rarely seen in nephroblastoma [11], but little is known of the description of osteoid formation as much as seen in the present case. Meanwhile, ORTI, defined as an intracalyceal mass composed of osteoid trabeculae, osteoblast-like cells and a spindle cell component, arising from, and attached to the medullary pyramid, also shows marked osteoid formation, and transition of spindle cells to osteoblast-like cells with osteoid which expressed EMA [5, 7, 14, 15], as seen in the present case. However, the luminal epithelial cells present in ORTI are not considered to be neoplastic cells. Since the present case is composed of malignant epithelial component and osteosarcoma-like mesenchymal component, it is considered different from ORTI.

Beta-catenin plays an important role in cell adhesion as a cadherin lining protein in the cell membrane and is an essential effector of the Wnt signaling pathway [1]. The Wnt signaling pathway is not only widely involved in the control of embryogenesis, it is also involved in the hereditary deseases and development of tumors [13]. Recently, $\beta$-catenin is known to promote transformation of mesenchymal cell into osteogenic cells [10], and to be deeply involved in tumorigenesis [8]. In the present case, also, $\beta$-catenin may play a role in marked osteoid formation and development of this tumor. In fact, the poorly differentiated tumor cells were positive for $\beta$-catenin and showed morphological transformation ino the osteoblast-like cells.

Although, the malignant features such as high mitotic index and atypia in the luminal epithelium were seen in the present case, it was difficult to assert that this tumor is malignant because there were no metastasis and invasion.

\section{REFERENCES}

1. Dale, T. C. 1998. Signal transduction by the Wnt family of ligands. Biochem. J. 329: 209-223. [Medline] [CrossRef]

2. Grieco, V., Riccardi, E., Belotti, S. and Scanziani, E. 2006. Immunohistochemical study of porcine nephroblastoma. J. Comp. Pathol. 134: 143-151. [Medline] [CrossRef]

3. Grubb, G. R., Yun, K., Williams, B. R., Eccles, M. R. and Reeve, A. E. 1994. Expression of WT1 protein in fetal kidneys and Wilms tumors. Lab. Invest. 71: 472-479. [Medline]

4. Hard, G. C. and Fox, R. R. 1983. Histologic characterization of renal tumors (nephroblastomas) induced transplacentally in IIIVO/J and WH/J rabbits by N-ethylnitrosourea. Am. J. Pathol. 113: 8-18. [Medline]

5. Ito, J., Shinohara, N., Koyanagi, T. and Hanioka, K. 1998. Ossifying renal tumor of infancy: the first Japanese case with long-term follow-up. Pathol. Int. 48: 151-159. [Medline] [CrossRef]

6. Kashima, T., Hirata, K. and Nomura, Y. 1995. Detection of porcine tumor cases at the meet inspection office of Kanagawa Prefecture in $1970-1990$. J. Jpn. Vet. Med. Assoc. 48: 436-440 (in Japanese with English summary). [CrossRef]

7. Keen, C. E. 2004. Ossifying renal tumor of infancy. p. 62. In: Pathology and Genetics of Tumours of the Urinary System and Male Genital Organs, World Health Organization Classification of Tumors. (John, N. E., Guido, S., Jonathan, I. E. and Isabell, A. S. eds.), IARC Press, Lyon.

8. Kikuchi, A. 2003. Tumor formation by genetic mutations in the components of the Wnt signaling pathway. Cancer Sci. 94: 225-229. [Medline] [CrossRef]

9. Kusewitt, F. D. and Rush, L. J. 2007. Neoplasia and tumor biology. pp. 253-298. In: Pathologic Basis of Veterinary Desease 4th ed. (McGavin, D. M. and Zachary, F. J. eds.), Mosby, St. Louis.

10. Mbalaviele, G., Sheikh, S., Stains, J. P., Salazar, V. S., Cheng, S. L., Chen, D. and Civitelli, R. 2005. $\beta$-catenin and BMP-2 synergize to promote osteoblast differentiation and new bone formation. J. Cell. Biochem. 94: 403-418. [Medline] [CrossRef]

11. Meuten, D. J. and Meuten, T. L. K. 2017. Tumor of the Urinary System. pp. 632-688. In: Tumors in Domestic Animals 5th ed. (Donald, J. M. ed.), Wiley Blackwell.

12. Nielsen, S. W., Mackey, L. J. and Misdorp, W. 1976. Tumors of the kidney. Bull. World Health Organ. 53: 237-246. [Medline]

13. Polakis, P. 2000. Wnt signaling and cancer. Genes Dev. 14: 1837-1851. [Medline]

14. Sotelo-Avila, C., Beckwith, J. B. and Johnson, J. E. 1995. Ossifying renal tumor of infancy: a clinicopathologic study of nine cases. Pediatr. Pathol. Lab. Med. 15: 745-762. [Medline] [CrossRef]

15. The Committee on Histological Classification of Childhood Tumors, The Japanese Society of Pathology. 2008. Histological Classification and Color Atlas of Tumors in Infancy and Childhood vol 4., Kinbara Publishing Co., Tokyo (in Japanese).

16. Zini, E., Bovero, A., Nigrisoli, E., Ratto, A., Rampazzo, A. and Zatelli, A. 2003. Sarcomatoid renal cell carcinoma with osteogenic differentiation and paraneoplastic hepatopathy in a dog, possibly related to human Stauffer's syndrome. J. Comp. Pathol. 129: 303-307. [Medline] [CrossRef] 